\section{PARTICIPATION IN SPORT AS AN ASSESSMENT OF} WOMEN EMPOWERMENT

Bipin Kumar Dubey, ${ }_{1}^{1}$ Binayak Kumar Dubey, ${ }^{2}$ Jayashree Acharya ${ }^{1}{ }^{1}$ Lakshmibai National University of Physical Education, Gwalior, Madhya Pradesh, India; ${ }^{2}$ Department of Physical Education and Sports, Sakaldiha PG College, Sakaldiha, Uttar Pradesh, India

\subsection{6/bjsm.2010.078725.208}

According to National Policy for the Empowerment of Women (2001) section 6.2 'A holistic approach to women's health which includes both nutrition and health services will be adopted and special attention will be given to the needs of women and the girl at all stages of the life cycle'. The present study examines empowerment of women through games and sports keeping in view the physical, mental and social health. One hundred and fifty college going female subjects, age ranging between 18 and 25 years with a mean and SD of $21.26 \pm 2.07$ from different District of Gwalior, India were administered a self developed questionnaire. The various responses received were analysed using percentage. Study shows that participation in games and sports makes them physically active (44\%), improve their health $(42 \%)$, positive feeling of well being $(45 \%)$, prevention of chronic disease $(45 \%)$, prevention of osteoporosis $(41 \%)$. Further, sports and games relieves emotional strain (58\%), makes them to think logically (36\%), reduces anxiety, depression and stress $(38 \%)$, enhance decision making, organisational and management skill over time (46\%), foster self-esteem and empowerment $(30 \%)$, offers more freedom in comparison to past (58\%), opportunities for leadership and achievement
$(56 \%)$, economic and social development (61\%), encourages women to form clubs and hence have a career in sport (48\%). Majority of the women had a favourable attitude towards participation in games and sports thus helping to improve their physical, mental, and social health. Gender violence $(68 \%)$ and discrimination (56\%) can be reduced if more and more females participated in sports. Further, sports helps in providing equal status to women. 